\title{
$\beta$-Carboline Alkaloids and Essential Tremor: Exploring the Environmental Determinants of One of the Most Prevalent Neurological Diseases
}

\author{
Elan D. Louis ${ }^{1,2,3,4, *}$ and Wei Zheng ${ }^{5}$ \\ ${ }^{1}$ GH Sergievsky Center, ${ }^{2}$ Department of Neurology, ${ }^{3}$ Taub Institute for Research on \\ Alzheimer's Disease and the Aging Brain, College of Physicians and Surgeons, \\ Columbia University, New York; ${ }^{4}$ Department of Epidemiology, Mailman School of \\ Public Health, Columbia University, New York; ${ }^{5}$ School of Health Sciences, Purdue \\ University, West Lafayette, IN
}

E-mail: EDL2@columbia.edu; wzheng@purdue.edu

Received May 24, 2010; Revised July 15, 2010; Accepted July 15, 2010; Published September 1, 2010

Essential tremor (ET) is among the most prevalent neurological diseases, yet its etiology is not well understood. Susceptibility genotypes undoubtedly underlie many ET cases, although no genes have been identified thus far. Environmental factors are also likely to contribute to the etiology of ET. Harmane (1-methyl-9H-pyrido[3,4$\beta$ ]indole) is a potent, tremor-producing $\beta$-carboline alkaloid, and emerging literature has provided initial links between this neurotoxin and ET. In this report, we review this literature. Two studies, both in New York, have demonstrated higher blood harmane levels in ET cases than controls and, in one study, especially high levels in familial ET cases. Replication studies of populations outside of New York and studies of brain harmane levels in ET have yet to be undertaken. A small number of studies have explored several of the biological correlates of exposure to harmane in ET patients. Studies of the mechanisms of this putative elevation of harmane in ET have explored the role of increased dietary consumption, finding weak evidence of increased exogenous intake in male ET cases, and other studies have found initial evidence that the elevated harmane in ET might be due to a hereditarily reduced capacity to metabolize harmane to harmine (7-methoxy-1-methyl-9H-pyrido[3,4- $\beta]$-indole). Studies of harmane and its possible association with ET have been intriguing. Additional studies are needed to establish more definitively whether these toxic exposures are associated with ET and are of etiological importance.

KEYWORDS: essential tremor, environmental epidemiology, etiology, toxin, harmane

\section{INTRODUCTION}

Essential tremor (ET) is a chronic neurological disease that is usually progressive. Its hallmark clinical feature is a 4- to $12-\mathrm{Hz}$ kinetic tremor (i.e., tremor that occurs during volitional movements) of the 
arms[1], which may manifest during a broad range of daily tasks (e.g., eating, writing, and shaving) (Fig. 1). Across affected individuals, this tremor may range in severity from mild and functionally inconsequential to severe and disabling[2,3,4,5]. In addition to the classical kinetic tremor of the arms, patients may exhibit a variety of tremors that differ by location (e.g., head, voice, and jaw) and condition (postural, intentional, and rest)[1,6,7,8]. Aside from tremor, other motor manifestations have been documented; perhaps most notable of these is a gait that has been described as mildly ataxic $[9,10]$. In addition, there is growing recognition of the presence of mild cognitive changes (especially executive dysfunction) $[11,12,13,14,15,16]$. In epidemiological studies, ET has been shown to be associated with increased risks of Alzheimer's disease[17,18] and Parkinson's disease[19]. Although traditionally viewed as a disease of morbidity rather than mortality, in the single, prospective, population-based study that enrolled a control group, there was a $45 \%$ increased risk of mortality[20], despite the absence of such a finding in one earlier retrospective study using historical controls[21].

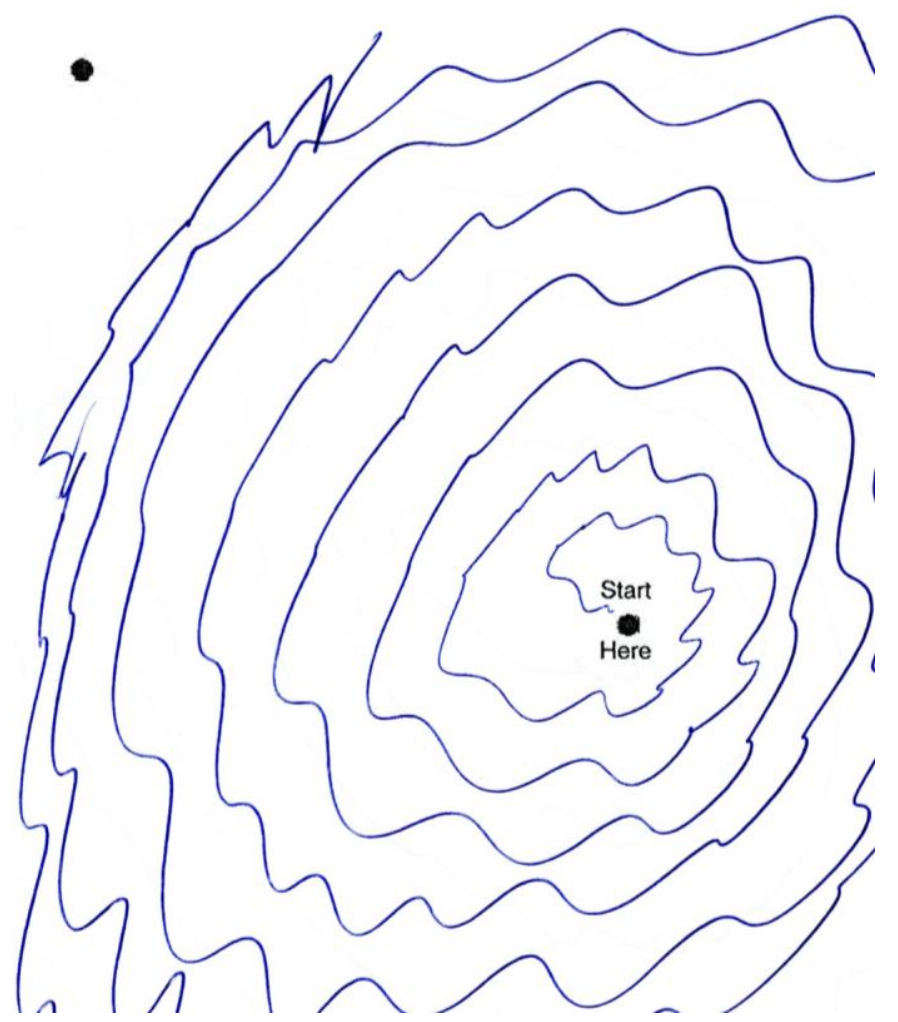

FIGURE 1. The effects of tremor are apparent in an ET patient's attempt to draw an Archimedes spiral.

ET is one of the most common neurological diseases; in a meta-analysis of the 28 population-based prevalence studies, the pooled prevalence (all ages) $=0.9 \%[22]$. A commonly cited value is that the population prevalence is $4.0 \%$ after age 39 years[23]. The prevalence increases markedly with age, especially with advanced age (i.e., $4.6 \%$ among persons aged 65 years and older, and as high as $21.7 \%$ in persons aged 95 and older)[22].

The underlying pathogenesis of ET is poorly understood, although recent postmortem studies indicate the presence of degenerative changes in the cerebellum in the majority of cases, including Purkinje cell loss in excess of that seen in similarly aged controls[24,25]. 


\section{ETIOLOGY OF ET}

The common presence, in clinic samples, of ET families with multiple affected individuals over several generations has led to the view that genetic susceptibility is of importance in disease etiology[26]. Although no genes have yet been identified, linkage to regions on chromosome 2p[27], 3q[28], and $6 \mathrm{p}[29]$ indicate that genetic factors are indeed of importance in this disease. A commonly cited value is that $50 \%$ of ET cases occur on a familial basis[30,31].

Although widely considered to have a large genetic component, it is likely that environmental factors also contribute to the etiology of ET[32]. The high preponderance of ET cases without affected relatives (>50\% of ET cases in some series) $[31,33,34,35,36,37,38]$ and the results from concordance studies (60\% concordance in monozygotic twins in one study and $63 \%$ in another)[39,40] are among the observations that have been used to support the notion that nongenetic factors are important in this disease[32,41]. The existence of intrafamilial differences in age of onset and severity of tremor[42,43] also suggests that environmental (or perhaps other genetic) factors may be serving as modifiers of underlying susceptibility genotypes.

Environmental factors are also thought to play a substantial role in other neurological disorders (Parkinson's disease, Alzheimer's disease, amyotrophic lateral sclerosis)[44,45,46,47,48,49,50,51,52, $53,54,55]$, so that it is not inconceivable that they could play a role in ET. Using the commonly cited value of $50 \%$ for the percentage of cases that occur on a familial basis[30,31] and given its population prevalence of $4.0 \%$ after age 39 years[23], this then suggests that approximately $2.0 \%$ of the population aged $\geq 40$ years has a nonfamilial form of ET[23,32]. Despite the apparent extent of the problem, the environmental correlates for this tremor are just beginning to be explored. One possible link has been established with the exposure to $\beta$-carboline alkaloids. The purpose of this article is to critically review the published literature on the links between $\beta$-carboline alkaloids and ET.

\section{$\beta$-CARBOLINES AS POSSIBLE ENVIRONMENTAL TOXINS IN ET}

\section{Rationale for Their Study in ET}

The $\beta$-carboline alkaloids are a group of naturally occurring, tremor-producing chemicals that include harmane, harmine, harmaline, and several others $[32,56,57,58]$. Structurally, the $\beta$-carboline alkaloids are heterocyclic amines, comprised of a combination of five- and six-ringed (i.e., cyclic) carbon structures, containing an amine group[59,60] (Fig. 2). There is considerable structural similarity with 1-methyl-4phenyl-1,2,3,6-tetrahydropyridine (MPTP), which is used to produce one of the main toxin-induced animal models for Parkinson's disease[61,62,63]. Like MPTP, the $\beta$-carboline alkaloids are highly neurotoxic, and the administration of $\beta$-carboline alkaloids to a wide variety of laboratory animals produces an intense and generalized action tremor that resembles ET[32,64]. Indeed, $\beta$-carboline alkaloid administration is currently viewed as the main animal model for ET and new pharmacotherapies are tested using exposed animals $[65,66,67,68,69]$. The tremor that is produced by $\beta$-carboline alkaloids shares several features with ET, including its primary clinical features and drug-response characteristics $[69,70,71,72,73,74]$, and underlying brain changes (destructive changes in the cerebellum, including Purkinje cell loss, which has now been documented in ET and in the $\beta$-carboline alkaloid model of tremor)[25,64,69,70,75,76,77,78,79]. Human volunteers exposed to intravenously administered harmine exhibit neurological signs, including an acute, coarse tremor[80,81].

Harmane (1-methyl-9H-pyrido[3,4- $\beta$ ]indole) is a potent, tremor-producing $\beta$-carboline alkaloid[56], capable of inducing tremor in laboratory animals within $3.1 \mathrm{~min}$ of subcutaneous injection[57]. Due to its high lipid solubility, harmane accumulates in brain tissue, with brain concentrations in laboratory animals 6.5 times those injected into peripheral tissues[57]. Furthermore, harmane is one of the most abundant of all dietary heterocyclic amines and human exposure to harmane through diet is greater than that of other heterocyclic amines[82,83], making it a $\beta$-carboline alkaloid of particularly high interest in epidemiological studies of humans[32]. 


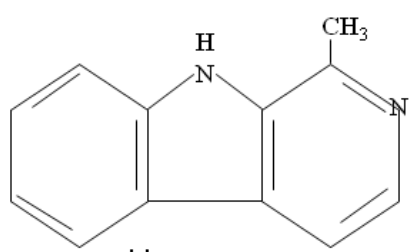

Harmane

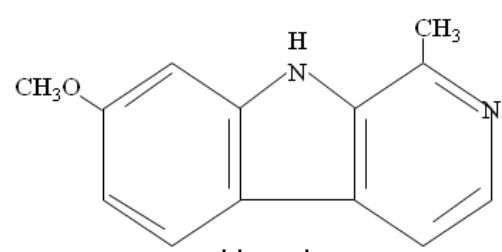

Harmine

FIGURE 2. Chemical structures of harmane (1-methyl-9H-pyrido[3,4- $\beta]$ indole) and harmine (7-methoxy-1-methyl-9H-pyrido[3,4- $\beta]$-indole).

$\beta$-Carboline alkaloids are produced by the body endogenously[84,85], although exogenous sources are likely to be more important; one study estimated that dietary sources were 50 times greater than these endogenous sources[86]. $\beta$-Carboline alkaloids may be found in particularly high $\mathrm{ng} / \mathrm{g}$ concentrations in animal protein (i.e., meat) and cooking results in additional increases in concentrations $[83,87,88,89,90]$. $\beta$-Carboline alkaloids are also present in varying concentrations in a variety of plant-derived foods/substances, including coffee, ethanol, and tobacco[32,91]. The demonstrated tremor-inducing property of the $\beta$-carboline alkaloids, along with their presence in the food supply, provides the rationale for an in-depth scrutiny of their potential role in the etiology of ET, the most common tremor disorder.

\section{Are Levels Elevated in ET?}

Hypothesizing that $\beta$-carboline alkaloids might be an environmental exposure of etiological importance in ET, Louis and colleagues began to study their blood concentrations in ET cases in 2000[60,92]. Concentrating their efforts on harmane, which is one of the most abundant of all dietary heterocyclic amines[82,83], and harmine (7-methoxy-1-methyl-9H-pyrido[3,4- $\beta]$-indole), a probable metabolic breakdown product of harmane[60], they demonstrated that blood harmane concentration was elevated in 100 ET cases at the Neurological Institute of New York compared to 100 matched control subjects (median blood harmane [cases] $=5.21$ vs. $2.28 \mathrm{~g}^{-10} / \mathrm{mL}$ [controls], $p=0.005$ )[93]. Blood harmine concentrations were also marginally, but not significantly, elevated in ET cases (median blood harmine [cases] $=1.60$ vs. $0.65 \mathrm{~g}^{-10} / \mathrm{mL}$ [controls], $p=0.19$ ). A larger replicate sample of 150 ET cases and 135 matched controls was assembled over the ensuing 5 years (2002-2007)[94]; while overall concentrations were lower in that sample, the case-control difference persisted (median blood harmane [cases] $=2.61$ vs. $1.82 \mathrm{~g}^{-10} / \mathrm{mL}$ [controls], $p=0.016$ )[94]. Among ET cases, there was no correlation between blood harmane concentration and tremor severity (total tremor score, Pearson's $r=-0.01, p=0.87$ ), yet in a small subgroup of 24 ET cases with very severe tremor (total tremor score $\geq 25$ ), blood harmane concentrations were very high. In linear regression analysis in which log blood harmane concentration was the outcome variable, the ordinal independent variable was coded as follows: ET with high total tremor score (2), remainder of ET cases (1), and controls (0), beta $=0.16, p=0.03$, indicating a significant trend (i.e., as one progressed from controls to ET cases and finally to ET cases with severe tremor, blood harmane concentration progressively increased)[94].

These two studies provide preliminary evidence for elevated blood harmane concentrations in ET. There is, however, a need to replicate these data at other centers with additional ET case samples.

\section{Are Levels Elevated in the ET Brain?}

Levels of harmane have been shown to be elevated in the blood in two studies to date. This result is intriguing; however, the brain is the presumptive target organ for harmane-induced effects in patients with 
ET. Are brain levels of harmane elevated in ET? Data are indirect and very limited and will be reviewed below.

Magnetic resonance spectroscopic imaging studies[95,96] have demonstrated reductions in the $N$ acetyl aspartate to creatine ratio in the cerebellum of ET cases compared with controls. $N$-Acetyl aspartate is an amino acid that is present in the cytosol of neurons and is a marker of neuronal integrity. Reductions in $N$-acetyl aspartate (often expressed as a ratio to brain creatine) are a marker of neuronal damage and probable neuronal loss[97,98]. These reductions in the $N$-acetyl aspartate to creatine ratio in the ET cerebellum are consistent with postmortem studies that have documented degenerative changes, including Purkinje cell loss, in the ET cerebellum[79,99]. Hypothesizing that blood harmane concentration in ET cases would be inversely correlated with cerebellar NAA/tCR, a neuroimaging measure of neuronal dysfunction or degeneration, Louis et al.[100] used magnetic resonance spectroscopic imaging to assess 12 ET cases in a pilot study. A priori, the neuroanatomic structure of interest was the cerebellar cortex. Secondary regions were the central cerebellar white matter, cerebellar vermis, thalamus, and basal ganglia. Blood concentrations of harmane and another neurotoxin, lead, were also assessed. In a linear regression model that adjusted for age and gender, log blood harmane concentration was a predictor of cerebellar NAA/tCR $(p=0.009)$ such that every $1 \mathrm{~g}^{-10} / \mathrm{mL}$ unit increase in log blood harmane concentration was associated with a 0.41 unit decrease in cerebellar NAA/tCR. The association between blood harmane concentration and brain NAA/tCR only occurred in the cerebellar cortex; it was not observed in any of the secondary brain regions of interest. Furthermore, the association was specific to harmane and not lead[100]. These results provide preliminary support for the view that increased blood harmane concentration in ET is associated with cerebellar neuronal damage, consistent with the animal study data that harmane and other $\beta$-carboline alkaloids produce cerebellar damage[64,69,70,75, $76,77,78]$. Of course, this pilot study did not directly measure brain harmane concentration in ET cases, and studies of human postmortem tissue are needed in order to test the association between brain harmane levels and ET directly.

\section{Other Possible Biological Correlates of Elevated Harmane in ET}

In a number of studies of ET patients, additional biological correlates of elevated harmane have been examined in an attempt to explore the wider biological effects of this toxin. In the first study[101], the association between elevated blood harmane and impaired olfaction was explored. Olfactory dysfunction occurs in a variety of diseases, including patients with cerebellar diseases[102,103], and there is evidence that the cerebellum itself may play a role in central olfactory processing[102,103,104,105]. Olfactory dysfunction has also been reported in patients with ET in some studies[106]. As noted above, the pathophysiology of ET is not well understood, although recent postmortem studies indicate the presence of degenerative changes in the cerebellum[24,25]. $\beta$-Carboline alkaloids have been shown to produce marked cerebellar damage in exposed laboratory animals in several studies[70,77]. To further test the model that harmane, through cerebellar toxicity, leads to ET, Louis et al.[101] hypothesized that they would find a correlation between blood harmane concentrations and smell test scores in ET cases (i.e., higher blood harmane concentration would be associated with greater olfactory dysfunction) and furthermore, that such a correlation would not be detected among a group of controls. In that study of 83 ET cases and 69 controls, they indeed found that higher blood harmane concentration was correlated with lower smell test scores in ET cases (rho $=-0.46, p<0.001$ ); however, in controls, higher blood harmane concentration was not correlated with lower smell test scores (rho $=0.12, p=0.32)[101]$.

In a second study, Louis et al.[107] examined associations between harmane and cancer. Many of the heterocyclic amines are also mutagens and are linked with several types of cancer (especially colon and prostate) $[59,108,109]$. Harmane itself is not mutagenic, yet it exerts comutagenic activity both in bacterial and mammalian cells[110,111]. Harmane is a comutagen and a high blood concentration could conceivably predispose an individual to cancer. As noted above, blood harmane concentrations also seem to be elevated in initial studies of ET patients[93,94]. Louis et al.[107], therefore, tested the hypothesis 
that particularly high blood harmane concentrations might be found among patients with both conditions (i.e., ET and cancer). In a study of 147 ET cases and 187 controls, log blood harmane concentration was highest in ET cases with cancer $\left(0.87 \pm 0.68 \mathrm{~g}^{-10} / \mathrm{mL}\right)$, intermediate in ET cases without cancer $(0.54 \pm$ $\left.0.60 \mathrm{~g}^{-10} / \mathrm{mL}\right)$, and lowest in controls $\left(0.43 \pm 0.69 \mathrm{~g}^{-10} / \mathrm{mL}\right)(p=0.009)$ [107], providing some support for this hypothesis.

Each of the studies discussed above examined additional biological correlates of elevated harmane in ET, further strengthening the notion that harmane exposure has a biological effect in this group of patients.

\section{What is the Mechanism for the Elevated Blood Harmane Level in ET?}

The mechanism for the putative elevation in blood harmane level in ET has not been established. A number of possibilities exist, including increased dietary intake, impaired ability to metabolize harmane (likely genetic), increased endogenous production of harmane (likely genetic), or a combination of these. Data are limited, but the evidence for or against each hypothesis will be reviewed.

As noted above, harmane is found in high concentrations in cooked meats, although there are no data relating the quantity and type of meat ingested with specific postprandial blood harmane levels. Looking at dietary differences, in 2005, Louis et al.[112] compared the levels of daily animal protein consumption in a sample of 106 ET cases and 161 controls. Total daily animal protein consumption was similar in the two groups (50.2 \pm 19.6 vs. $49.4 \pm 19.1 \mathrm{~g} /$ day, $p=0.74)$. However, the study used a standardized food frequency questionnaire[113] that included only a small number of questions to assess meat consumption. In a follow-up study[114], a more detailed meat consumption questionnaire was utilized. In the follow-up study[114], total meat consumption was greater in men with ET vs. men without ET (135.3 \pm 71.1 vs. $110.6 \pm 80.4 \mathrm{~g} /$ day, $p=0.03$ ), but not in women with ET vs. without ET ( $80.6 \pm 50.0$ vs. $79.3 \pm 51.0$ $\mathrm{g} /$ day, $p=0.76$ ). Male ET cases had a higher odds of being in the highest vs. lowest quartile of current meat consumption than did male controls (unadjusted odds ratio $[\mathrm{OR}]=9.29,95 \%$ confidence interval $[\mathrm{CI}]=2.29-37.64, p=0.002$, adjusted $\mathrm{OR}=21.36,95 \% \mathrm{CI}=3.52-129.51, p=0.001)$. The study provided preliminary evidence of a dietary difference between males with ET vs. males without ET[114], raising the question whether this possible dietary difference, through harmane consumption, could be linked with ET. Yet the data are very preliminary. First, if some males were eating more meat and developing ET, then one might expect a higher prevalence of ET among males, yet most population-based prevalence studies point to a similar prevalence of ET among males and females rather than a higher prevalence among males[22]. Second, in a population-based study of Hindus in India, many of whom are vegetarian, the prevalence of ET was low $(0.35 \%)$, but it was similar to other studies of nonvegetarians that used a two-phase approach (i.e., a screen followed by an examination) to capture ET cases[115]. Third, as noted above, cooking meat at higher temperatures for longer periods produces higher harmane concentrations in the meat[90]. Hence, one might expect ET cases to have been eating meat that was more well done than controls. In the dietary study[114], level of meat "doneness" was assessed and was similar in male ET cases and male controls, as well as female ET cases and controls.

An alternative possibility is that the elevated harmane in ET is due to an inherited reduction in the capacity to metabolize harmane. In the replicate sample in New York, Louis et al.[94] stratified ET cases based on family history of ET. The ET cases with a family history of ET had the highest blood harmane concentration, followed by ET cases without a family history of ET, and then finally the controls, who had the lowest concentration $(p=0.026)$. This observation that blood harmane concentration was highest in familial ET cases provided some support for the notion that genetic/metabolic factors are of mechanistic importance[94]. As noted above, the metabolic pathway for harmane is not fully known, although it is probable that it is converted by the liver cytochrome P-450 system to harmine through simple hydroxylation and then methylation steps[60]. To further explore the genetic/metabolic hypothesis, Louis et al. (submitted for publication) recently examined data on blood concentrations of harmane and harmine in more than 500 individuals, comprised of three groups: familial ET, sporadic ET, 
and controls. The investigators hypothesized that defective metabolic conversion of harmane to harmine might underlie the observed elevated harmane concentration in ET, and therefore expected to find a higher harmane to harmine ratio in familial ET than in sporadic ET or controls. Indeed, the harmane/harmine ratio was highest in familial ET $(46.7 \pm 140.4)$, intermediate in sporadic ET $(28.3 \pm$ 108.1), and lowest in controls $(13.5 \pm 50.3)(p=0.03)$. These findings lend some support to the possibility that the basis for the elevated blood harmane concentration in ET is a genetically driven reduction in harmane metabolism.

A third possibility is that endogenous production of harmane is increased in ET cases. Unfortunately, the relative contributions of exogenous vs. endogenous harmane have not been determined in normal humans nor have they been determined among humans with certain disease states (e.g., ET). There are at present no data to test this possibility directly.

A combination of these factors is also a possibility (e.g., increased dietary exposure as well as decreased metabolic turnover in ET cases).

\section{Limitations of Current Studies}

As noted above, studies of harmane and its putative association with ET have been intriguing. Additional work is required in order to establish and then explore these links further. Although elevated harmane concentrations have been observed in blood samples of ET cases, at this time it is not known whether brain concentrations of this neurotoxin are elevated in ET. Second, current data were derived from studies of ET cases ascertained from a single center and they need to be reproduced elsewhere. Third, one study found elevated blood harmane concentrations in 36 patients with Parkinson's disease[116], which raises the question as to whether elevated blood harmane is specific to ET or is merely a more global marker of neurological illness. Addressing these additional questions would further delineate the associations between ET and this neurotoxin. One final caveat is as follows: the tremor-producing and neurotoxic properties of the $\beta$-carboline alkaloids have been presented in this paper. Some of these alkaloids may also have neuroprotective properties (e.g., 9-methyl- $\beta$-carboline has been shown to be protective of cultured dopaminergic neurons)[117]. Whether such properties are relevant to tremor disorders is unknown, but worthy of future consideration.

\section{SUMMARY AND CONCLUSIONS}

ET is a common and widespread neurological disease whose etiology is likely to be the result of both genetic and environmental factors. Heterogeneity of pathophysiology, which is becoming evident in postmortem studies[79,118,119], suggests that this disease itself may actually be more than one disease. Hence, establishing an etiological role for a particular neurotoxin is even more challenging, particularly as neurotoxins may be important for some, but not other, forms of the disease. Furthermore, while a neurotoxin by itself could be sufficient to cause a neurological disease, another possibility is that the toxin merely increases the propensity for developing the disorder. For example, a toxin might set in motion a set of biological changes (e.g., Purkinje cell loss), which then increase the exposed individual's sensitivity to a second toxic exposure (e.g., another neurotoxin) or a second nontoxic exposure (e.g., an increased genetic susceptibility to Purkinje cell loss).

Using the commonly cited value of $50 \%$ for the percentage of ET cases that occur on a familial basis[30,31] and given its population prevalence of $4.0 \%$ beginning at age 40 and older[23], this then suggests that approximately $2.0 \%$ of the population aged $\geq 40$ years has a nonfamilial form of ET[23,32]. Environmental etiologies are likely to be of prime importance not only in these cases, but they could also play a role in familial cases through gene-environment interactions. Yet environmental correlates for ET are just beginning to be explored. Initial studies of harmane are of interest, and the role that harmane might play in the etiology of ET deserves additional study using replicate samples of ET cases and brain 
tissue from such cases. If, indeed, harmane is an etiological agent of importance in ET, from a public health vantage point, one potential means to reduce or prevent the occurrence of ET might be to induce hepatic drug-metabolizing enzymes in the liver P450 system in at-risk individuals (e.g., individuals with a family history of ET).

\section{ACKNOWLEDGMENTS}

Elan D. Louis was funded by R01 NS39422, P30 ES09089, and RR00645 (General Clinical Research Center) from the National Institutes of Health (Bethesda, MD). Wei Zheng was funded by R01 NS39422, R01 ES008146, and R21 ES017055 from the National Institutes of Health (Research Triangle, NC). The National Institutes of Health played no role in the study design, the collection of data, the analysis and interpretation of data, the writing of the report, or in the decision to submit the paper for publication.

\section{REFERENCES}

1. $\quad$ Louis, E.D. (2001) Clinical practice. Essential tremor. N. Engl. J. Med. 345, 887-891.

2. Busenbark, K.L., Nash, J., Nash, S., Hubble, J.P., and Koller, W.C. (1991) Is essential tremor benign? Neurology 41, 1982-1983.

3. Bain, P.G., Findley, L.J., Thompson, P.D., Gresty, M.A., Rothwell, J.C., Harding, A.E., and Marsden, C.D. (1994) A study of hereditary essential tremor. Brain 117(Pt 4), 805-824.

4. Louis, E.D., Barnes, L., Albert, S.M., Cote, L., Schneier, F.R., Pullman, S.L., and Yu, Q. (2001) Correlates of functional disability in essential tremor. Mov. Disord. 16, 914-920.

5. Koller, W., Biary, N., and Cone, S. (1986) Disability in essential tremor: effect of treatment. Neurology 36, 10011004

6. Leegwater-Kim, J., Louis, E.D., Pullman, S.L., Floyd, A.G., Borden, S., Moskowitz, C.B., and Honig, L.S. (2006) Intention tremor of the head in patients with essential tremor. Mov. Disord. 21, 2001-2005.

7. $\quad$ Louis, E.D. (2005) Essential tremor. Lancet Neurol. 4, 100-110.

8. Cohen, O., Pullman, S., Jurewicz, E., Watner, D., and Louis, E.D. (2003) Rest tremor in patients with essential tremor: prevalence, clinical correlates, and electrophysiologic characteristics. Arch. Neurol. 60, 405-410.

9. Singer, C., Sanchez-Ramos, J., and Weiner, W.J. (1994) Gait abnormality in essential tremor. Mov. Disord. 9, 193196.

10. Stolze, H., Petersen, G., Raethjen, J., Wenzelburger, R., and Deuschl, G. (2001) The gait disorder of advanced essential tremor. Brain 124, 2278-2286.

11. Lombardi, W.J., Woolston, D.J., Roberts, J.W., and Gross, R.E. (2001) Cognitive deficits in patients with essential tremor. Neurology 57, 785-790.

12. Lacritz, L.H., Dewey, R., Jr., Giller, C., and Cullum, C.M. (2002) Cognitive functioning in individuals with "benign" essential tremor. J. Int. Neuropsychol. Soc. 8, 125-129.

13. Duane, D.D. and Vermilion, K.J. (2002) Cognitive deficits in patients with essential tremor. Neurology 58, 1706.

14. Sahin, H.A., Terzi, M., Ucak, S., Yapici, O., Basoglu, T., and Onar, M. (2006) Frontal functions in young patients with essential tremor: a case comparison study. J. Neuropsychiatry Clin. Neurosci. 18, 64-72.

15. Gasparini, M., Bonifati, V., Fabrizio, E., Fabbrini, G., Brusa, L., Lenzi, G.L., and Meco, G. (2001) Frontal lobe dysfunction in essential tremor: a preliminary study. J. Neurol. 248, 399-402.

16. Benito-Leon, J., Louis, E.D., and Bermejo-Pareja, F. (2006) Population-based case-control study of cognitive function in essential tremor. Neurology 66, 69-74.

17. Bermejo-Pareja, F., Louis, E.D., and Benito-Leon, J. (2007) Risk of incident dementia in essential tremor: a population-based study. Mov. Disord. 22, 1573-1580.

18. Thawani, S.P., Schupf, N., and Louis, E.D. (2009) Essential tremor is associated with dementia: prospective population-based study in New York. Neurology 73, 621-625.

19. Benito-Leon, J., Louis, E.D., and Bermejo-Pareja, F. (2009) Risk of incident Parkinson's disease and parkinsonism in essential tremor: a population based study. J. Neurol. Neurosurg. Psychiatry 80, 423-425.

20. Louis, E.D., Benito-Leon, J., Ottman, R., and Bermejo-Pareja, F. (2007) A population-based study of mortality in essential tremor. Neurology 69, 1982-1989.

21. Rajput, A.H., Offord, K.P., Beard, C.M., and Kurland, L.T. (1984) Essential tremor in Rochester, Minnesota: a 45-year study. J. Neurol. Neurosurg. Psychiatry 47, 466-470.

22. Louis, E.D. and Ferreira, J.J. (2010) How common is the most common adult movement disorder? Update on the worldwide prevalence of essential tremor. Mov. Disord. 25, 534-541. 
23. Dogu, O., Sevim, S., Camdeviren, H., Sasmaz, T., Bugdayci, R., Aral, M., Kaleagasi, H., Un, S., and Louis, E.D. (2003) Prevalence of essential tremor: door-to-door neurologic exams in Mersin Province, Turkey. Neurology 61, 1804-1806.

24. Louis, E.D., Faust, P.L., Vonsattel, J.-P.G., Honig, L.S., Rajput, A., Robinson, C.A., Rajput, A., Pahwa, R., Lyons, K.E., Ross, G.W., Borden, S., Moskowitz, C.B., Lawton, A., and Hernandez, N. (2007) Neuropathological changes in essential tremor: 33 cases compared with 21 controls. Brain 130, 3297-3307.

25. Axelrad, J.E., Louis, E.D., Honig, L.S., Flores, I., Ross, G.W., Pahwa, R., Lyons, K.E., Faust, P.L., and Vonsattel, J.P. (2008) Reduced purkinje cell number in essential tremor: a postmortem study. Arch. Neurol. 65, 101-107. Deng, H., Le, W., and Jankovic, J. (2007) Genetics of essential tremor. Brain 130, 1456-1464.

Mov. Disord. 12, 859-864.

Gulcher, J.R., Jonsson, P., Kong, A., Kristjansson, K., Frigge, M.L., Karason, A., Einarsdottir, I.E., Stefansson, H., Einarsdottir, A.S., Sigurthoardottir, S., Baldursson, S., Bjornsdottir, S., Hrafnkelsdottir, S.M., Jakobsson, F., Benedickz, J., and Stefansson, K. (1997) Mapping of a familial essential tremor gene, FET1, to chromosome 3q13. Nat. Genet. 17, 84-87.

29. Shatunov, A., Sambuughin, N., Jankovic, J., Elble, R., Lee, H.S., Singleton, A.B., Dagvadorj, A., Ji, J., Zhang, Y., Kimonis, V.E., Hardy, J., Hallett, M., and Goldfarb, L.G. (2006) Genomewide scans in North American families reveal genetic linkage of essential tremor to a region on chromosome 6p23. Brain 129, 2318-2331.

30. Lambert, D. and Waters, C.H. (1999) Essential tremor. Curr. Treat. Options Neurol. 1, 6-13.

31. Louis, E.D. and Ottman, R. (1996) How familial is familial tremor? The genetic epidemiology of essential tremor. Neurology 46, 1200-1205.

32. Louis, E.D. (2008) Environmental epidemiology of essential tremor. Neuroepidemiology 31, $139-149$.

33. Hornabrook, R.W. and Nagurney, J.T. (1976) Essential tremor in Papua, New Guinea. Brain 99, 659-672. Critchley, E. (1972) Clinical manifestations of essential tremor. J. Neurol. Neurosurg. Psychiatry 35, 365-372.

Salemi, G., Aridon, P., Calagna, G., Monte, M., and Savettieri, G. (1998) Population-based case-control study of essential tremor. Ital. J. Neurol. Sci. 19, 301-305.

37. Aiyesimoju, A.B., Osuntokun, B.O., Bademosi, O., and Adeuja, A.O. (1984) Hereditary neurodegenerative disorders Martinelli, P., Gabellini, A.S., Gulli, M.R., and Lugaresi, E. (1987) Different clinical features of essential tremor: a 200-patient study. Acta Neurol. Scand. 75, 106-111. in Nigerian Africans. Neurology 34, 361-362.

38. Dogu, O., Louis, E.D., Sevim, S., Kaleagasi, H., and Aral, M. (2005) Clinical characteristics of essential tremor in Mersin, Turkey--a population-based door-to-door study. J. Neurol. 252, 570-574.

39. Tanner, C.M., Goldman, S.M., Lyons, K.E., Aston, D.A., Tetrud, J.W., Welsh, M.D., Langston, J.W., and Koller, W.C. (2001) Essential tremor in twins: an assessment of genetic vs environmental determinants of etiology. Neurology 57, 1389-1391.

40. Lorenz, D., Frederiksen, H., Moises, H., Kopper, F., Deuschl, G., and Christensen, K. (2004) High concordance for essential tremor in monozygotic twins of old age. Neurology 62, 208-211.

41. Louis, E.D. (2001) Etiology of essential tremor: should we be searching for environmental causes? Mov. Disord. 16, $822-829$.

42. Larsson, T. and Sjogren, T. (1960) Essential tremor: a clinical and genetic population study. Acta Psychiatr. Scand. Suppl. 36, 1-176.

43. Louis, E.D., Ford, B., Frucht, S., Barnes, L.F., X-Tang, M., and Ottman, R. (2001) Risk of tremor and impairment from tremor in relatives of patients with essential tremor: a community-based family study. Ann. Neurol. 49, 761-769. Gorell, J.M., Johnson, C.C., Rybicki, B.A., Peterson, E.L., Kortsha, G.X., Brown, G.G., and Richardson, R.J. (1999) Occupational exposure to manganese, copper, lead, iron, mercury and zinc and the risk of Parkinson's disease. Neurotoxicology 20, 239-247.

45. Gorell, J.M., Johnson, C.C., Rybicki, B.A., Peterson, E.L., Kortsha, G.X., Brown, G.G., and Richardson, R.J. (1997) Occupational exposures to metals as risk factors for Parkinson's disease. Neurology 48, 650-658.

46. Gorell, J.M., Johnson, C.C., Rybicki, B.A., Peterson, E.L., and Richardson, R.J. (1998) The risk of Parkinson's disease with exposure to pesticides, farming, well water, and rural living. Neurology 50, 1346-1350.

47. Rybicki, B.A., Johnson, C.C., Uman, J., and Gorell, J.M. (1993) Parkinson's disease mortality and the industrial use of heavy metals in Michigan. Mov. Disord. 8, 87-92.

48. Racette, B.A., McGee-Minnich, L., Moerlein, S.M., Mink, J.W., Videen, T.O., and Perlmutter, J.S. (2001) Weldingrelated parkinsonism: clinical features, treatment, and pathophysiology. Neurology 56, 8-13.

49. Baldereschi, M., Inzitari, M., Vanni, P., Di Carlo, A., and Inzitari, D. (2007) Pesticide exposure might be a strong risk factor for Parkinson's disease. Ann. Neurol. 63, 128.

50. Dick, F.D. (2006) Parkinson's disease and pesticide exposures. Br. Med. Bull. 79-80, 219-231.

51. Ritz, B. and Yu, F. (2000) Parkinson's disease mortality and pesticide exposure in California 1984-1994. Int. J. Epidemiol. 29, 323-329.

52. Semchuk, K.M., Love, E.J., and Lee, R.G. (1992) Parkinson's disease and exposure to agricultural work and pesticide chemicals. Neurology 42, 1328-1335. 
53. Shcherbatykh, I. and Carpenter, D.O. (2007) The role of metals in the etiology of Alzheimer's disease. J. Alzheimers Dis. 11, 191-205.

54. Perl, D.P. (1985) Relationship of aluminum to Alzheimer's disease. Environ. Health Perspect. 63, 149-153.

55. Morahan, J.M., Yu, B., Trent, R.J., and Pamphlett, R. (2007) Genetic susceptibility to environmental toxicants in ALS. Am. J. Med. Genet. B Neuropsychiatr. Genet. 144, 885-890.

56. McKenna, D.J. (1996) Plant hallucinogens: springboards for psychotherapeutic drug discovery. Behav. Brain Res. 73, 109-116.

57. Zetler, G., Singbartl, G., and Schlosser, L. (1972) Cerebral pharmacokinetics of tremor-producing harmala and iboga alkaloids. Pharmacology 7, 237-248.

58. Sakai, S. (1995) [Chemical studies of indole alkaloids]. Yakugaku Zasshi 115, 351-369.

59. De Meester, C. (1995) Genotoxic potential of beta-carbolines: a review. Mutat. Res. 339, 139-153.

60. Guan, Y., Louis, E.D., and Zheng, W. (2001) Toxicokinetics of tremorogenic natural products, harmane and harmine, in male Sprague-Dawley rats. J. Toxicol. Environ. Health A 64, 645-660.

61. Langston, J.W., Langston, E.B., and Irwin, I. (1984) MPTP-induced parkinsonism in human and non-human primates-clinical and experimental aspects. Acta Neurol. Scand. Suppl. 100, 49-54.

62. Smeyne, R.J. and Jackson-Lewis, V. (2005) The MPTP model of Parkinson's disease. Brain Res. Mol. Brain Res. 134, 57-66.

63. Serra, P.A., Pluchino, S., Marchetti, B., Desole, M.S., and Miele, E. (2008) The MPTP mouse model: cues on DA release and neural stem cell restorative role. Parkinsonism Relat. Disord. 14(Suppl 2), S189-193.

64. Du, W., Aloyo, V.J., and Harvey, J.A. (1997) Harmaline competitively inhibits [3H]MK-801 binding to the NMDA receptor in rabbit brain. Brain Res. 770, 26-29.

65. Martin, F.C. and Handforth, A. (2006) Carbenoxolone and mefloquine suppress tremor in the harmaline mouse model of essential tremor. Mov. Disord. 21, 1641-1649.

66. Martin, F.C., Thu Le, A., and Handforth, A. (2005) Harmaline-induced tremor as a potential preclinical screening method for essential tremor medications. Mov. Disord. 20, 298-305.

67. Krahl, S.E., Martin, F.C., and Handforth, A. (2004) Vagus nerve stimulation inhibits harmaline-induced tremor. Brain Res. 1011, 135-138.

68. Handforth, A. and Krahl, S.E. (2001) Suppression of harmaline-induced tremor in rats by vagus nerve stimulation. Mov. Disord. 16, 84-88.

69. Sinton, C.M., Krosser, B.I., Walton, K.D., and Llinas, R.R. (1989) The effectiveness of different isomers of octanol as blockers of harmaline-induced tremor. Pflugers Arch. 414, 31-36.

70. Milner, T.E., Cadoret, G., Lessard, L., and Smith, A.M. (1995) EMG analysis of harmaline-induced tremor in normal and three strains of mutant mice with Purkinje cell degeneration and the role of the inferior olive. J. Neurophysiol. 73, $2568-2577$.

71. Trouvin, J.H., Jacqmin, P., Rouch, C., Lesne, M., and Jacquot, C. (1987) Benzodiazepine receptors are involved in tabernanthine-induced tremor: in vitro and in vivo evidence. Eur. J. Pharmacol. 140, 303-309.

72. Fuentes, J.A. and Longo, V.G. (1971) An investigation on the central effects of harmine, harmaline and related betacarbolines. Neuropharmacology 10, 15-23.

73. Cross, A.J., Misra, A., Sandilands, A., Taylor, M.J., and Green, A.R. (1993) Effect of chlormethiazole, dizocilpine and pentobarbital on harmaline-induced increase of cerebellar cyclic GMP and tremor. Psychopharmacology (Berl.) 111, 96-98.

74. Rappaport, M.S., Gentry, R.T., Schneider, D.R., and Dole, V.P. (1984) Ethanol effects on harmaline-induced tremor and increase of cerebellar cyclic GMP. Life Sci. 34, 49-56.

75. O'Hearn, E., Long, D.B., and Molliver, M.E. (1993) Ibogaine induces glial activation in parasagittal zones of the cerebellum. Neuroreport 4, 299-302.

76. O'Hearn, E. and Molliver, M.E. (1993) Degeneration of Purkinje cells in parasagittal zones of the cerebellar vermis after treatment with ibogaine or harmaline. Neuroscience 55, 303-310.

77. O'Hearn, E. and Molliver, M.E. (1997) The olivocerebellar projection mediates ibogaine-induced degeneration of Purkinje cells: a model of indirect, trans-synaptic excitotoxicity. J. Neurosci. 17, 8828-8841.

78. Robertson, H.A. (1980) Harmaline-induced tremor: the benzodiazepine receptor as a site of action. Eur. J. Pharmacol. 67, 129-132.

79. Louis, E.D., Faust, P.L., Vonsattel, J.P., Honig, L.S., Rajput, A., Robinson, C.A., Pahwa, R., Lyons, K.E., Ross, G.W., Borden, S., Moskowitz, C.B., Lawton, A., and Hernandez, N. (2007) Neuropathological changes in essential tremor: 33 cases compared with 21 controls. Brain 130, 3297-3307.

80. Lewin, L. (1928) Untersuchungen Uber Banisteria caapi Sp. Arch. Exp. Pathol. Pharmacol. 129, $133-149$.

81. Pennes, H.H. and Hoch, P.H. (1957) Psychotomimetics, clinical and theoretical considerations: harmine, Win-2299 and nalline. Am. J. Psychiatry 113, 887-892.

82. Skog, K., Augustsson, K., Steineck, G., Stenberg, M., and Jagerstad, M. (1997) Polar and non-polar heterocyclic amines in cooked fish and meat products and their corresponding pan residues. Food Chem. Toxicol. 35, 555-565.

83. Skog, K., Solyakov, A., Arvidsson, P., and Jagerstad, M. (1998) Analysis of nonpolar heterocyclic amines in cooked foods and meat extracts using gas chromatography-mass spectrometry. J. Chromatogr. A 803, 227-233. 
84. Gearhart, D.A., Collins, M.A., Lee, J.M., and Neafsey, E.J. (2000) Increased beta-carboline 9N-methyltransferase activity in the frontal cortex in Parkinson's disease. Neurobiol. Dis. 7, 201-211.

85. Wakabayashi, K., Totsuka, Y., Fukutome, K., Oguri, A., Ushiyama, H., and Sugimura, T. (1997) Human exposure to mutagenic/carcinogenic heterocyclic amines and comutagenic beta-carbolines. Mutat. Res. 376, 253-259.

86. Pfau, W. and Skog, K. (2004) Exposure to beta-carbolines norharman and harman. J. Chromatogr. B Analyt. Technol. Biomed. Life Sci. 802, 115-126.

87. Gross, G.A., Turesky, R.J., Fay, L.B., Stillwell, W.G., Skipper, P.L., and Tannenbaum, S.R. (1993) Heterocyclic aromatic amine formation in grilled bacon, beef and fish and in grill scrapings. Carcinogenesis 14, 2313-2318.

88. Skog, K. (1993) Cooking procedures and food mutagens: a literature review. Food Chem. Toxicol. 31, $655-675$.

89. Layton, D.W., Bogen, K.T., Knize, M.G., Hatch, F.T., Johnson, V.M., and Felton, J.S. (1995) Cancer risk of heterocyclic amines in cooked foods: an analysis and implications for research. Carcinogenesis 16, 39-52.

90. Louis, E.D., Zheng, W., Jiang, W., Bogen, K.T., and Keating, G.A. (2007) Quantification of the neurotoxic betacarboline harmane in barbecued/grilled meat samples and correlation with level of doneness. J. Toxicol. Environ. Health A 70, 1014-1019.

91. Herraiz, T. (2004) Relative exposure to beta-carbolines norharman and harman from foods and tobacco smoke. Food Addit. Contam. 21, 1041-1050.

92. Zheng, W., Wang, S., Barnes, L.F., Guan, Y., and Louis, E.D. (2000) Determination of harmane and harmine in human blood using reversed-phased high-performance liquid chromatography and fluorescence detection. Anal. Biochem. 279, 125-129.

93. Louis, E.D., Zheng, W., Jurewicz, E.C., Watner, D., Chen, J., Factor-Litvak, P., and Parides, M. (2002) Elevation of blood beta-carboline alkaloids in essential tremor. Neurology 59, 1940-1944.

94. Louis, E.D., Jiang, W., Pellegrino, K.M., Rios, E., Factor-Litvak, P., Henchcliffe, C., and Zheng, W. (2008) Elevated blood harmane (1-methyl-9H-pyrido[3,4-b]indole) concentrations in essential tremor. Neurotoxicology 29, 294-300.

95. Louis, E.D., Shungu, D.C., Chan, S., Mao, X., Jurewicz, E.C., and Watner, D. (2002) Metabolic abnormality in the cerebellum in patients with essential tremor: a proton magnetic resonance spectroscopic imaging study. Neurosci. Lett. 333, 17-20.

96. Pagan, F.L., Butman, J.A., Dambrosia, J.M., and Hallett, M. (2003) Evaluation of essential tremor with multi-voxel magnetic resonance spectroscopy. Neurology 60, 1344-1347.

97. Tedeschi, G., Bertolino, A., Campbell, G., Barnett, A.S., Duyn, J.H., Jacob, P.K., Moonen, C.T., Alger, J.R., and Di Chiro, G. (1996) Reproducibility of proton MR spectroscopic imaging findings. AJNR Am. J. Neuroradiol. 17, 18711879.

98. Vion-Dury, J., Nicoli, F., Salvan, A.M., Confort-Gouny, S., Dhiver, C., and Cozzone, P.J. (1995) Reversal of brain metabolic alterations with zidovudine detected by proton localised magnetic resonance spectroscopy. Lancet 345, 6061.

99. Louis, E.D. and Vonsattel, J.P. (2007) The emerging neuropathology of essential tremor. Mov. Disord. 23, $174-182$.

100. Louis, E.D., Zheng, W., Mao, X., and Shungu, D.C. (2007) Blood harmane is correlated with cerebellar metabolism in essential tremor: a pilot study. Neurology 69, 515-520.

101. Louis, E.D., Rios, E., Pellegrino, K.M., Jiang, W., Factor-Litvak, P., and Zheng, W. (2008) Higher blood harmane (1methyl-9H-pyrido[3,4-b]indole) concentrations correlate with lower olfactory scores in essential tremor. Neurotoxicology 29, 294-300.

102. Connelly, T., Farmer, J.M., Lynch, D.R., and Doty, R.L. (2003) Olfactory dysfunction in degenerative ataxias. $J$. Neurol. Neurosurg. Psychiatry 74, 1435-1437.

103. Velazquez-Perez, L., Fernandez-Ruiz, J., Diaz, R., Gonzalez, R.P., Ochoa, N.C., Cruz, G.S., Mederos, L.E., Gongora, E.M., Hudson, R., and Drucker-Colin, R. (2006) Spinocerebellar ataxia type 2 olfactory impairment shows a pattern similar to other major neurodegenerative diseases. J. Neurol. 253, 1165-1169.

104. Sobel, N., Prabhakaran, V., Hartley, C.A., Desmond, J.E., Zhao, Z., Glover, G.H., Gabrieli, J.D., and Sullivan, E.V. (1998) Odorant-induced and sniff-induced activation in the cerebellum of the human. J. Neurosci. 18, 8990-9001.

105. Deiss, V. and Baudoin, C. (1997) Hyposmia for butanol and vanillin in mutant staggerer male mice. Physiol. Behav. 61, 209-213.

106. Applegate, L.M. and Louis, E.D. (2005) Essential tremor: mild olfactory dysfunction in a cerebellar disorder. Parkinsonism Relat. Disord. 11, 399-402.

107. Louis, E.D., Pellegrino, K.M., Factor-Litvak, P., Rios, E., Jiang, W., Henchcliffe, C., and Zheng, W. (2008) Cancer and blood concentrations of the comutagen harmane in essential tremor. Mov. Disord. 23, 1747-1751.

108. Bogen, K.T., Keating, G.A., 2nd, Chan, J.M., Paine, L.J., Simms, E.L., Nelson, D.O., and Holly, E.A. (2007) Highly elevated PSA and dietary PhIP intake in a prospective clinic-based study among African Americans. Prostate Cancer Prostatic Dis. 10, 261-269.

109. Armbrecht, H.J., Lakshmi, V.M., Wickstra, J., Hsu, F.F., and Zenser, T.V. (2007) Metabolism of a heterocyclic amine colon carcinogen in young and old rats. Drug Metab. Dispos. 35, 633-639.

110. Totsuka, Y., Ushiyama, H., Ishihara, J., Sinha, R., Goto, S., Sugimura, T., and Wakabayashi, K. (1999) Quantification of the co-mutagenic beta-carbolines, norharman and harman, in cigarette smoke condensates and cooked foods. Cancer Lett. 143, 139-143. 
111. Boisset, M., Billaud, C., and Desjeux, J.F. (1994) Studies on the mechanism of intestinal passage of the food comutagen harman, in the rabbit. Food Chem. Toxicol. 32, 349-356.

112. Louis, E.D., Zheng, W., Applegate, L., Shi, L., and Factor-Litvak, P. (2005) Blood harmane concentrations and dietary protein consumption in essential tremor. Neurology 65, 391-396.

113. Willett, W.C., Sampson, L., Stampfer, M.J., Rosner, B., Bain, C., Witschi, J., Hennekens, C.H., and Speizer, F.E. (1985) Reproducibility and validity of a semiquantitative food frequency questionnaire. Am. J. Epidemiol. 122, 51-65.

114. Louis, E.D., Keating, G.A., Bogen, K.T., Rios, E., Pellegrino, K.M., and Factor-Litvak, P. (2008) Dietary epidemiology of essential tremor: meat consumption and meat cooking practices. Neuroepidemiology 30, $161-166$.

115. Das, S.K., Biswas, A., Roy, J., Bose, P., Roy, T., Banerjee, T.K., Mukherjee, C., Raut, D.K., Chowdhury, A., and Hazra, A. (2008) Prevalence of major neurological disorders among geriatric population in the metropolitan city of Kolkata. J. Assoc. Physicians India 56, 175-181.

116. Kuhn, W., Muller, T., Grosse, H., and Rommelspacher, H. (1995) Plasma harman and norharman in Parkinson's disease. J. Neural Transm. Suppl. 46, 291-295.

117. Polanski, W., Enzensperger, C., Reichmann, H., and Gille, G. (2010) The exceptional properties of 9-methyl-betacarboline: stimulation, protection and regeneration of dopaminergic neurons coupled with anti-inflammatory effects. $J$. Neurochem. 113, 1659-1675.

118. Louis, E.D., Erickson-Davis, C., Pahwa, R., Lyons, K.E., Garber, A., Moskowitz, C.B., Lawton, A., Faust, P.L., and Vonsattel, J.P. (2010) Essential tremor with ubiquitinated Purkinje cell intranuclear inclusions. Acta Neuropathol. 119, 375-377.

119. Shill, H.A., Adler, C.H., Sabbagh, M.N., Connor, D.J., Caviness, J.N., Hentz, J.G., and Beach, T.G. (2008) Pathologic findings in prospectively ascertained essential tremor subjects. Neurology 70, 1452-1455.

\section{This article should be cited as follows:}

Louis, E.D. and Zheng, W. (2010) $\beta$-Carboline alkaloids and essential tremor: exploring the environmental determinants of one of the most prevalent neurological diseases. TheScientificWorldJOURNAL 10, 1783-1794. DOI 10.1100/tsw.2010.159. 


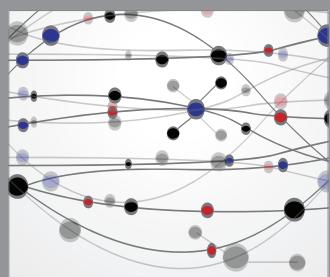

The Scientific World Journal
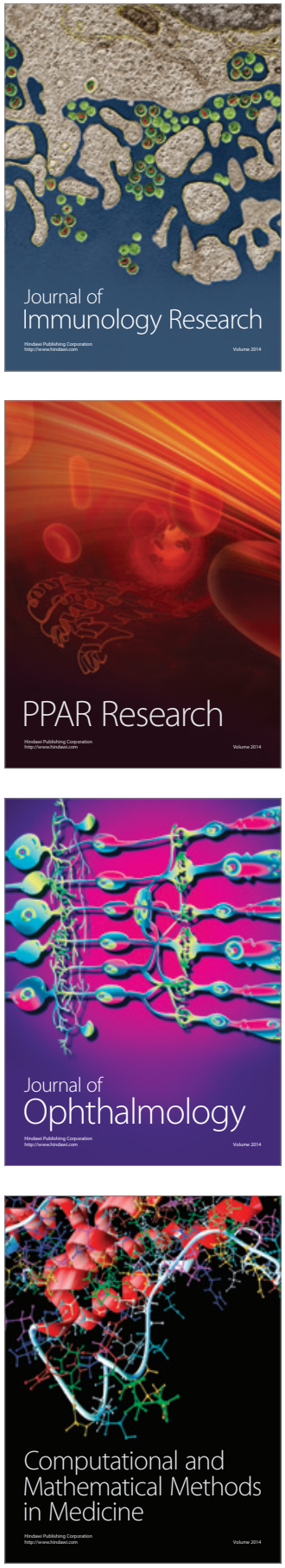

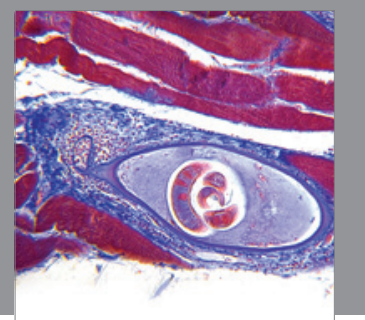

Gastroenterology

Research and Practice
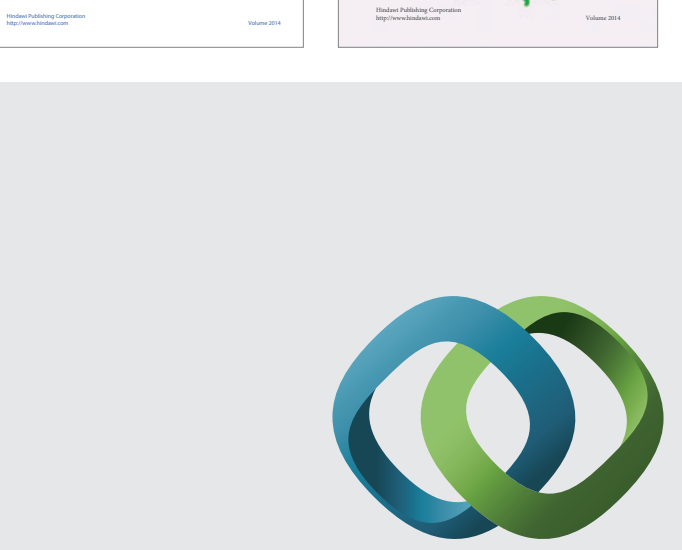

\section{Hindawi}

Submit your manuscripts at

http://www.hindawi.com
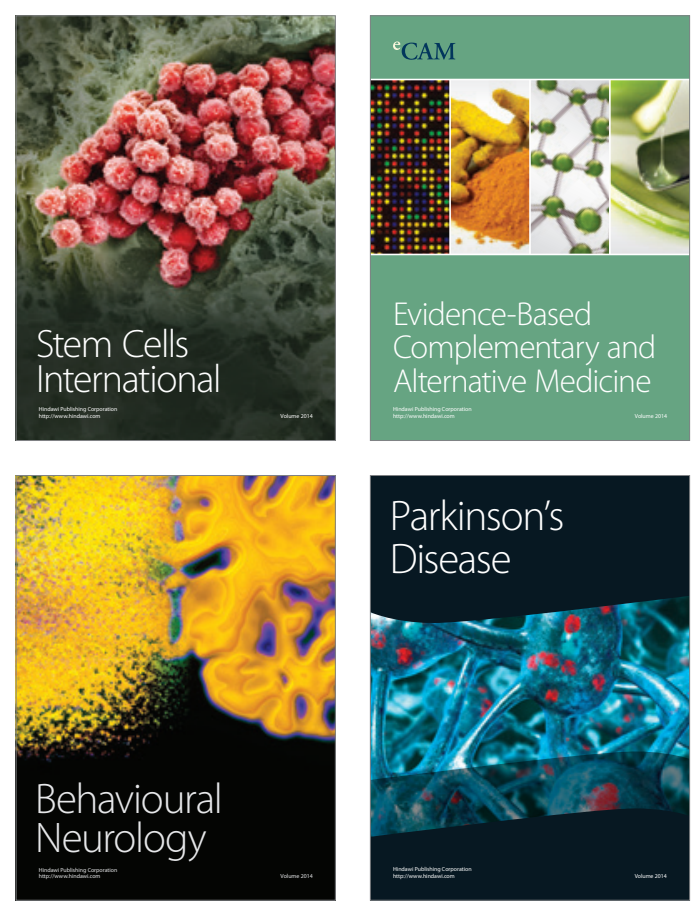

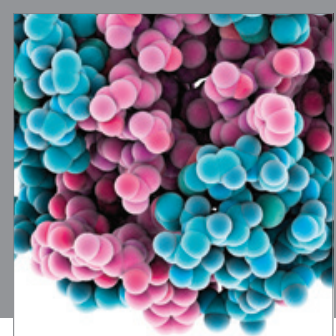

Journal of
Diabetes Research

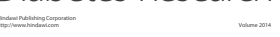

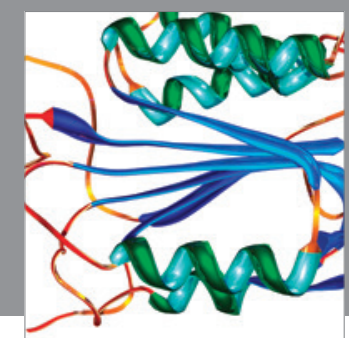

Disease Markers
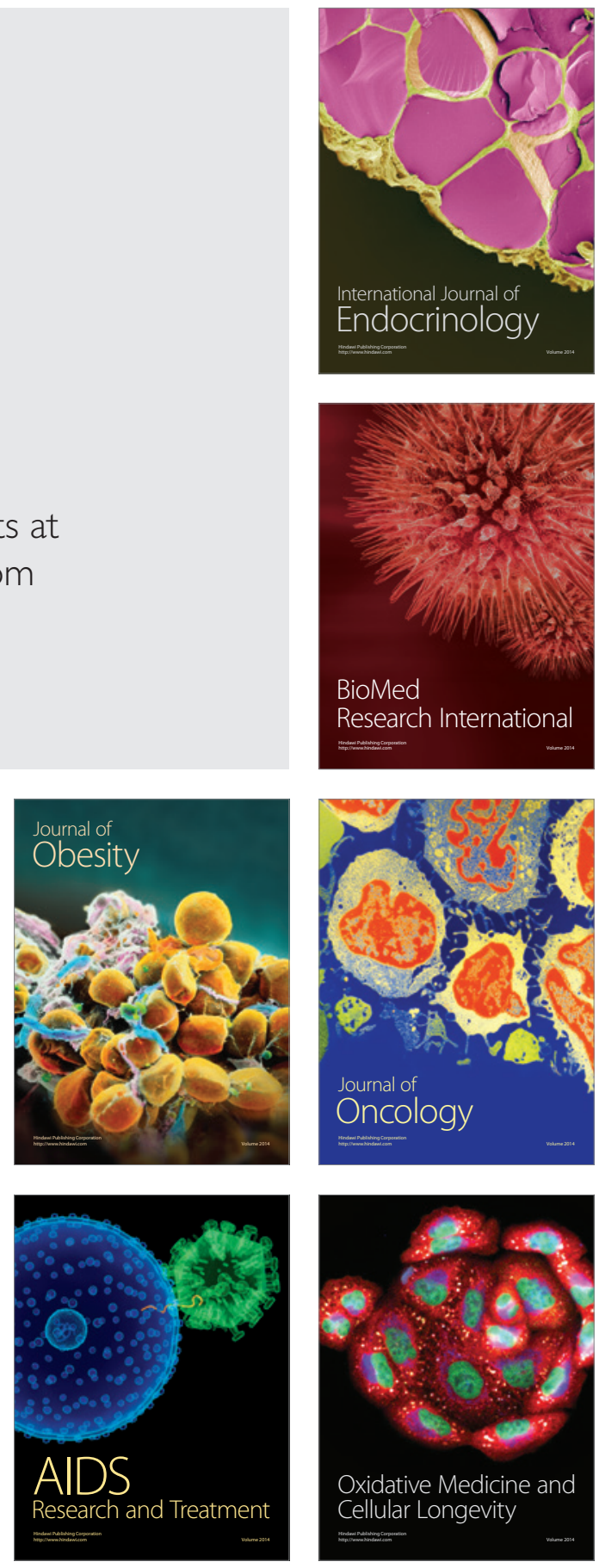